\title{
Impact of clopidogrel in coronary artery bypass grafting ${ }^{\hbar 3}$
}

\author{
Lars Englberger ${ }^{\mathrm{a}}$, Bettina Faeh $^{\mathrm{a}}$, Pascal A. Berdat ${ }^{\mathrm{a}}$, Franz Eberli $^{\mathrm{b}}$, \\ Bernhard Meier $^{\mathrm{b}}$, Thierry Carrel $^{\mathrm{a}, *}$

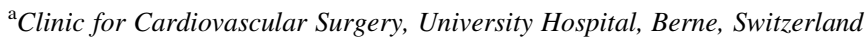 \\ ${ }^{\mathrm{b}}$ Division of Cardiology, University Hospital, Berne, Switzerland
}

Received 18 October 2003; received in revised form 15 March 2004; accepted 22 March 2004; Available online 18 May 2004

\begin{abstract}
Objective: Clopidogrel has become the standard of care to prevent thrombotic complications following cardiological interventions, in particular intracoronary stenting. In addition, patients with aspirin intolerance and those with carotid and peripheral vascular disease are also increasingly treated with clopidogrel. Platelet inhibition may become a concern for hemostasis in patients treated with clopidogrel who need emergency and undelayed surgery. Methods: We prospectively analyzed the intra- and postoperative outcome of 505 consecutive patients who underwent isolated CABG and compared two groups: those with clopidogrel exposure until $72 \mathrm{~h}$ prior to surgery $(n=136)$ with those without exposition to clopidogrel $(n=369)$. Patients undergoing emergency surgery because of failed PTCA and cardiogenic shock, associated valvular surgery, redo-CABG, and those with additional platelet IIb/IIIa receptor inhibitor exposure were excluded. Patients who received aspirin and/or heparin treatment prior to surgery were not excluded. Results: Patients who received clopidogrel had a higher prevalence of angina class III or IV (67 vs 39\%, $P<0.01)$, received more often revascularization within $48 \mathrm{~h}(41 \mathrm{vs} 14 \%, P=0.02)$, and had received more frequently stenting ( $57 \mathrm{vs} 13 \%$ ). Chest tube drainage was significantly increased during the first $24 \mathrm{~h}$ following CABG in the group of patients who had clopidogrel treatment ( $1485 \mathrm{vs} 780 \mathrm{ml}, P=0.003$ ) These patients also required more transfusion of platelets and fresh frozen plasma. Overall re-exploration rate because of bleeding was significantly higher in the clopidogrel group (5.9 vs $1.2 \%$, $P<0.01)$. Platelets transfused before chest closure had a beneficial effect on preservation of the hemostasis. Conclusions: Clopidogrel exposure 3 days or less prior to CABG surgery significantly increases the risk of postoperative bleeding, the need for perioperative transfusion and the incidence of re-exploration. Surgery should be performed using standard heparinization and anti-fibrinolytic strategies but aggressive correction of platelets dysfunction is required before chest closure.
\end{abstract}

(C) 2004 Elsevier B.V. All rights reserved.

Keywords: Coronary artery bypass grafting; Clopidogrel; Antiplatelet therapy; Blood loss; Transfusion requirements

\section{Introduction}

During the last decade, a multitude of antiplatelets and anticoagulatory agents have been used in patients with coronary artery disease, especially in the periprocedural period of PTCA alone or following intracoronary stenting. The majority of these agents, including thienopyridines, particularly clopidogrel and ticlopidine, and glycoproteines IIb/IIIa inhibitors has been demonstrated to have beneficial effects on the outcome of intracoronary interventional procedures [1-3]. Moreover, ticlopidine and clopidogrel,

\footnotetext{
${ }^{27}$ Presented at the joint 17th Annual Meeting of the European Association for Cardio-thoracic Surgery and the 11th Annual Meeting of the European Society of Thoracic Surgeons, Vienna, Austria, October 12-15 2003.

* Corresponding author. Tel.: + 41-31-632-2375; fax: + 41-31-632-4443.

E-mail address: thierry.carrel@insel.ch (T. Carrel).
}

which act on the cyclic adenosine monophosphate pathway to irreversibly inhibit platelets, are increasingly popular substitutes for and/or complementary to aspirin in the management of thromboembolic and occlusive arterial disease.

Clopidogrel has emerged as the standard of care to prevent stent thrombosis in interventional cardiology. Patients with acute coronary syndrome and more recently those with carotid and peripheral vascular disease are also increasingly treated with clopidogrel [4-6]. Clopidogrel has the following advantages over the other thienopyridine ticlopidine: (1) the onset of action is shorter, (2) the time to reach a steady state following a loading dose of $300 \mathrm{mg}$ is shorter and (3) the incidence of side effects is significantly lower.

The cause of early postoperative bleeding following onpump CABG may be multifactorial; insufficient surgical 
hemostasis, disorders of the coagulation system due to hemodilution, platelets dysfunction as well as negative effects of the cardiopulmonary bypass circuit are the most common causes for impaired hemostasis [7,8]. Platelet inhibition by clopidogrel may become crucial for hemostasis in patients who need emergency surgery. On the other hand, the development of new strategies (for instance $\mathrm{OPCAB}$, miniaturization of $\mathrm{CPB}$ circuits, preoperative blood donation, acute normovolemic hemodilution) and some pharmacologic interventions (erythropoietine) have reduced the need for allogeneic blood transfusion and the rate of re-exploration for bleeding [8].

Aim of this study was to analyze the influence of Clopidogrel treatment on postoperative bleeding and transfusion requirements as well as on overall outcome in patients who received isolated myocardial revascularization in our institution.

\section{Methods}

We prospectively analyzed the early postoperative outcome of 505 consecutive patients who underwent primary isolated CABG and compared two groups of patients: those who received Clopidogrel within $72 \mathrm{~h}$ of surgery $(n=136)$ to those who did not receive Clopidogrel $(n=369)$. Patients undergoing emergency surgery because of failed PTCA and cardiogenic shock, patients scheduled for $\mathrm{CABG}$ combined to valvular surgery, redo-CABG, and those who received platelet IIb/IIIa receptor inhibitors were excluded. The main indications for Clopidogrel treatment are listed on Table 1. In five percent of the patients, no clearcut indication for clopidogrel administration could be found.

The main demographic characteristics of the patients, the operative strategy as well as the main perioperative and postoperative complications were recorded. The use of any additional antiplatelet medication other than Clopidogrel or oral anticoagulation treatment in the last 7 days prior to surgery was recorded. Length of stay on the intensive care unit and total hospitalization were also recorded.

Low-dose aprotinin was administrated in the pump prime ( 2 mio KIU) in all patients operated with the aid of cardiopulmonary bypass. In these patients, heparin (300 IU/kg) was administred before cannulation to reach a ACT value higher than $480 \mathrm{~s}$. Heparin reversal was achieved

Table 1

Main indications for clopidogrel treatment $(n=136)$

\begin{tabular}{ll}
\hline Prior percutaneous coronary intervention & $92(67.6 \%)$ \\
Unstable angina & $69(58 \%)$ \\
Acute myocardial infarction & $46(33.8 \%)$ \\
Intolerance of aspirin & $6(4.4 \%)$ \\
Cerebrovascular disease & $11(8 \%)$ \\
Peripheral vascular disease ( \pm PTA) & $16(11.7 \%)$ \\
Unclear indication & $13(9.5 \%)$ \\
\hline
\end{tabular}

Several indications in the same patient possible. with 1:1 protamine. In patients who underwent beating heart CABG (OPCAB), 2 mio KIU aprotinin were administred as a loading dose during induction of the anaesthesia and a continuous infusion of 500,000 KIU/h during the procedure. Heparin $(100 \mathrm{IU} / \mathrm{kg}$ ) was given immediately before flow interruption in the 1st target coronary vessel to reach an ACT value of approximately $250 \mathrm{~s}$. Heparin reversal was performed with half of the protamin dose.

During extracorporeal perfusion, transfusion of red blood cells was performed when hematocrite value decreased under 0.18. Postoperative transfusion of packed red blood cells was found to be indicated when hematocrite value was lower than 0.24. Platelets were transfused when the total count was lower than 80,000 and there was a increasing and/or prolonged tendency of postoperative bleeding. The timing of platelet transfusion (before chest closure or later on the intensive care unit) was examined. Surgical reexploration was found to be indicated when bleeding exceeded $400 \mathrm{ml}$ during the first hour or when it was more than $300 \mathrm{ml} / \mathrm{h}$ during the next $3 \mathrm{~h}$ despite normalized ACT and global coagulation status.

Preoperative hematocrite and the lowest intraoperative hematocrite value were recorded. Total chest tube drainage during the first $24 \mathrm{~h}$, the incidence of re-exploration and the early outcome (mortality, incidence of major complications, duration of mechanical ventilation, stay in the intensive care unit and total hospitalization time) were assessed. Finally the exposure to blood products was analyzed.

\subsection{Statistical analysis}

Main clinical characteristics (age, gender, cardiovascular risk factors, functional class, Euroscore value) of patients with and without clopidogrel were recorded; an additional analysis was performed to compare on-pump patients and OPCAB patients separately. Fisher's exact or chi-square test was used to compare differences in proportions. Continuous variables are expressed as mean $\pm \mathrm{SD}$ and were compared with parametric (Student's t-test) or nonparametric (Wilcoxon test) based on the distribution of variables. A two-tailed $P<0.05$ was considered to be statistically significant. Multivariate analysis with a logistic regression was performed to determine whether preoperative clopidogrel was an independent risk factor for re-exploration, increased drainage output through the chest tubes during the first $24 \mathrm{~h}$ and the need for transfusion of packed red cells and platelets.

Statistical analysis was performed with SPSS software version.

\section{Results}

There was no significant difference in the main demographic characteristics of the patients between the 2 groups with or without Clopidogrel; within the subset of 
Table 2

Demographic data

\begin{tabular}{llll}
\hline & Clopidogrel & No Clopidogrel & $P$-value \\
\hline Number of patients & 136 & 369 & \\
Gender m:f & $104: 32$ & $286: 83$ & $\mathrm{~ns}$ \\
Age (years) & $66 \pm 10.6$ & $68 \pm 8.4$ & $\mathrm{~ns}$ \\
Body mass index & $27.6 \pm 2.9$ & $26.9 \pm 4.1$ & $\mathrm{~ns}$ \\
Renal failure & $11(8 \%)$ & $37(10 \%)$ & $\mathrm{ns}$ \\
$\quad($ creatinin $>150 \mu \mathrm{mol} / \mathrm{l})$ & & & \\
\hline
\end{tabular}

OPCAB-patients, there was also no difference in demographic factors between those who had received Clopidogrel and those who did not (Table 2). Additional exposure to salicylic acid and to intravenous heparin was comparable between the different groups. Patients who received Clopidogrel had a higher prevalence of acute coronary syndrome (73 versus $16 \%, P<0.001$ ), angina functional class III or IV (67 vs 39\%, $P<0.01$ ), surgical revascularization within $48 \mathrm{~h}$ following cardiac catheterism (41 vs $14 \%, P=0.02$ ), and preoperative stenting (57 vs $13 \%$, $P<0.001$ ) (Table 3).

The intraoperative technical details (Table 4) as well as the intra- and perioperative anticoagulation management were comparable between the 2 groups. However some differences existed depending on the operative technique (OPCAB or on-pump). As expected, patients given Clopidogrel had a higher mean chest tube drainage $24 \mathrm{~h}$ after the procedure (1485 vs $780 \mathrm{ml}, P=0.003$ ), but there was a trend to decreased bleeding when platelets were transfused before chest closure as compared to transfusion once the operation had be terminated Table 5). Patients with Clopidogrel required more transfusion of platelets and fresh frozen plasma (Table 6). Thirty day-mortality was similar in both groups (Clopidogrel or not 1.4 vs $0.8 \%$ ) and for both operative techniques (on-pump and OPCAB, 0.9 vs $1.4 \%$ ) and was not dependent from urgency of revascularization. Overall re-exploration rate because of postoperative bleeding was significantly higher in the Copidogrel group (5.9 vs $1.2 \%, P<0.01)$. However, clinical outcome was comparable within both groups (Table 7).

Table 3

Cardiovascular history

\begin{tabular}{llll}
\hline & $\begin{array}{l}\text { Clopidogrel } \\
(n=136)\end{array}$ & $\begin{array}{l}\text { No clopidogrel } \\
(n=369)\end{array}$ & $P$-value \\
\hline $\begin{array}{l}\text { Prior myocardial infarction } \\
\text { Angina functional }\end{array}$ & $67 \%$ & $39 \%$ & $<0.01$ \\
$\quad$ class III or IV & & & $\mathrm{ns}$ \\
Ejection fraction (\%) & $44 \pm 7.5$ & $49 \pm 11$ & $\mathrm{~ns}$ \\
$\begin{array}{l}\text { Prior PTCA } \\
\text { Prior PTCA + stenting }\end{array}$ & $19 \%$ & $11 \%$ & $<0.001$ \\
$\begin{array}{l}\text { Surgery within 48 h } \\
\text { Mean Interval }\end{array}$ & $57 \%$ & $13 \%$ & 0.07 \\
$\quad$ PCI-surgery (d) & $91 \%$ & $14 \%$ & 0.097 \\
\hline
\end{tabular}

Table 4

Intraoperative data

\begin{tabular}{llll}
\hline & $\begin{array}{l}\text { Clopidogrel } \\
(n=136)\end{array}$ & $\begin{array}{l}\text { No clopidogrel } \\
(n=369)\end{array}$ & $P$-value \\
\hline $\begin{array}{l}\text { On-pump } \\
\begin{array}{l}\text { Pump-assisted } \\
\text { beating heart }\end{array}\end{array}$ & $\begin{array}{l}\text { a } \\
\text { 25/14/136(83.8\%) }\end{array}$ & $\begin{array}{l}320 / 369(86.7 \%) \\
29 / 320(9 \%)\end{array}$ & $\mathrm{ns}$ \\
$\begin{array}{l}\text { OPCAB } \\
\text { Number of coronary }\end{array}$ & $3.6 \pm 0.3$ & & \\
$\quad$ anastomoses & $22 / 136(16.2 \%)$ & $49 / 369(13.3 \%)$ & $\mathrm{ns}$ \\
$\begin{array}{l}\text { Bypass time (min) } \\
\text { Ischemia time (min) }\end{array}$ & $67 \pm 15$ & $3.8 \pm 0.5$ & $\mathrm{~ns}$ \\
\hline
\end{tabular}

${ }^{\text {a }}$ Minimal ECC system, on-pump beating heart, centrifugal pump.

\section{Discussion}

It is increasingly common for patients who need $\mathrm{CABG}$ surgery to be undergoing pharmacological alteration of hemostasis, because anti-platelet drugs have demonstrated considerable success in the treatment of acute coronary syndrome, including unstable angina and acute myocardial infarction and following percutaneous coronary interventions $[9,10]$. Acquired platelet dysfunction is one of the most commonly encountered hemostatic defects among patients undergoing surgical procedures, and drug-induced platelet dysfunction may turn out to be a major concern while hemostasis is performed. The main factors that may affect bleeding and transfusion requirements in these patients are: presence of risk factors for bleeding, proper transfusion practices, conserving or increasing the red cell mass, as well as appropriate heparin dosing and protamine reversal [11]. In particular, excess protamine should be avoided in these patients because of the adverse effects on coagulation factors and platelets [12].

Differentiating between postoperative bleeding due to coagulopathy and a surgical reason that should be corrected with re-exploration is not always straightforward in the early postoperative course, and this may additionally complicated by preoperative clopidogrel administration. There is only scarce literature about effects of Clopidogrel on bleeding after coronary artery bypass surgery, but in all

Table 5

Chest tube output and re-exploration

\begin{tabular}{lllr}
\hline & Clopidogrel & No clopidogrel & $P$-value \\
\hline Overall CABG & $(n=136)$ & $(n=369)$ & \\
$\quad$ Drainage (ml/24 h) & $1485 \pm 310$ & $780 \pm 105$ & 0.003 \\
Re-exploration & $8(5.9 \%)$ & $5(1.2 \%)$ & $<0.01$ \\
On pump & $(n=114)$ & $(n=320)$ & \\
Drainage (ml/24 h) & $1550 \pm 300$ & $850 \pm 140$ & 0.025 \\
Re-exploration & 7 & 4 & \\
OPCAB & $(n=22)$ & $(n=49)$ & 0.04 \\
Drainage (ml/24 h) & $1250 \pm 430$ & $660 \pm 170$ & \\
Re-exploration & 1 & 1 & \\
Diffuse bleeding & 7 & 3 & \\
Surgical bleeding & 1 & 2 & \\
\hline
\end{tabular}


Table 6

Transfusion data

\begin{tabular}{llll}
\hline & $\begin{array}{l}\text { Clopidogrel } \\
(n=136)\end{array}$ & $\begin{array}{l}\text { No clopidogrel } \\
(n=369)\end{array}$ & $P$-value \\
\hline $\begin{array}{l}\text { Transfusion } \\
\text { Packed red cells (units) }\end{array}$ & $4.6 \pm 2.3$ & $1.5 \pm 2.2$ & 0.027 \\
$\begin{array}{l}\text { Fresh frozen plasma (units) } \\
\text { Platelets (units) }\end{array}$ & $0.9 \pm 1.4$ & $0.3 \pm 0.9$ & $\mathrm{~ns}$ \\
Blood product exposure & $2.6 \pm 1.1$ & $0.2 \pm 0.6$ & 0.001 \\
$\begin{array}{l}\text { Red blood cells } \\
\text { Fresh frozen plasma }\end{array}$ & $92 \%$ & $47 \%$ & $<0.001$ \\
Platelets & $42 \%$ & $13 \%$ & 0.003 \\
\hline
\end{tabular}

reports available yet, it has been demonstrated that Clopidogrel-treated patients have increased rates of bleeding, transfusion of blood products and re-exploration for bleeding [9,13-15]. In a retrospective analysis including 128 aspirin-treated patients who received bilateral internal thoracic artery, 64 were additionally on Clopidogrel and 64 not. Both groups were comparable regarding demographics and intraoperative variables. Chest tube output was higher in the Clopidogrel group and was responsible for a higher rate of re-exploration 7.8 versus $0 \%$. The need for transfusion of blood products was higher in Clopidogreltreated patients but the stay on the intensive care station was not prolonged by these events [13].

Yende and Wunderlink reported their experience with 247 patients, out of which 51 received preoperative Clopidogrel. In this prospective observational cohort study designed to detect complications following CABG surgery, primary and secondary end points were need for reexploration because of bleeding, need for transfusion of blood products and chest tube output respectively. Unfortunately patients who received CABG combined to valve surgery were not excluded from this observation. Patients who received preoperative Clopidogrel (a large majority had also received aspirin and $45 \%$ intravenous heparin) had a higher incidence of re-exploration for bleeding and an increased need for packed red blood cells and cryoprecipitate transfusion. A large proportion of patients required urgent surgery $(71 \%)$ whereas only $20 \%$ were operated on an elective basis [14].

Table 7

Clinical outcome

\begin{tabular}{|c|c|c|c|}
\hline & $\begin{array}{l}\text { Clopidogrel } \\
(n=136)\end{array}$ & $\begin{array}{l}\text { No clopidogrel } \\
(n=369)\end{array}$ & $P$-value \\
\hline Mortality & $1.4 \%(2 / 136)$ & $0.8 \%(3 / 369)$ & ns \\
\hline Low cardiac output & $8.1 \%$ & $3.9 \%$ & 0.03 \\
\hline $\begin{array}{l}\text { Perioperative myocardial } \\
\text { infarction }\end{array}$ & $4.3 \%$ & $3.1 \%$ & ns \\
\hline Intubation longer than $12 \mathrm{~h}$ & $59 \%$ & $27 \%$ & 0.08 \\
\hline Mean ICU stay (d) & $1.9 \pm 1.3$ & $1.1 \pm 0.7$ & ns \\
\hline Mean hospitalization time (d) & $9.6 \pm 2.1$ & $7.9 \pm 2.0$ & ns \\
\hline
\end{tabular}

Hongo and co-authors prospectively compared 224 patients undergoing non-emergent $\mathrm{CABG}$ and examined the postoperative outcome of those with and those without Clopidogrel exposition. The Clopidogrel group had a higher chest tube output and more transfusion of red blood cells. The rate of re-exploration because of bleeding was 10 -fold higher in the Clopidogrel group, inducing thereby less extubation within $8 \mathrm{~h}$ and a trend towards less hospital discharge within 5 days [15].The role of preoperative Clopidogrel on postoperative outcome in patients undergoing OPCAB surgery is still not elucidated [16].

In cardiopulmonary bypass, in which platelet dysfunction is extremely common, the bleeding time has never been shown to have predictive value either preoperatively or postoperatively. However, considerable progress has been made in the clinical assessment of platelet function. Thromboelastography (TEG) for instance has gained popularity in the perioperative setting; it is used to test clot strengh over time through examination of the elastic shear modulus. Thromboelastography is now understood to test the interaction between fibrin and GP IIb/IIIa. Work with abciximab has shown a direct dose-dependent relation between drug and maximum amplitude during TEG. Some publications have shown it to be a useful predictor of abnormal postoperative bleeding after cardiac surgery [17]. TEG may be also be a useful tool to guide platelet transfusion. We have recently introduced TEG as a routine intraoperative examination but data were not available for the present trial.

This prospective observational study is limited by the fact that some preoperative characteristics, especially the rate of unstable angina and incidence of PCI prior to surgery were not similar in both groups. Furthermore, neither surgeons nor anesthesiologists were blinded to antiplatelet treatment received in the immediate preoperative period, which means that there was a potential for bias. However an usual perioperative management was applied in all patients. Despite the fact that a multivariate analysis was performed, the influence of intraoperative factors such as technique of operation (on-pump or OPCAB), type of bypass grafts, duration of $\mathrm{CPB}$ and cross-clamp time, could not be elucidated. Peri- and postoperative substitution of either fresh frozen plasma and platelets was based on coagulation parameters (platelets $<80,000 / \mathrm{ml}$, ACT $10 \%$ or more than baseline, pathologic INR, thrombin time and/or bleeding time). In case of complete absence of clotting following adequate reversal of heparin, platelets concentrates were transfused before closure of the chest.

The management of patients scheduled for CABG who are on Clopidogrel treatment is controversial. Some trials suggest that these patients should have surgery delayed until the platelet function recovers but the optimal duration of this delay needs further evaluation. In the CURE trial, patients that interrupted Clopidogrel treatment within 5 days prior to CABG had a trend towards more bleeding than those patients in the control placebo group [18]. The drug 
manufacturer recommends that clopidogrel should be discontinued for 7 days prior to elective coronary surgery. In all other cases, the risk of bleeding must be weighted against the risks of delaying the surgery (unstable angina, myocardial infarction, hemodynamic compromise) [19]. In our experience, Clopidogrel exposure within 3 days prior to CABG surgery significantly increases the risk of postoperative bleeding, the need for perioperative transfusion and surgical re-exploration. Considering the fact that a majority of patients receiving Clopidogrel are higher-risk patients than those who do not, the overall outcome (mortality and major cardiac or neurologic morbidity) is still very acceptable. This experience does not justify to delay the surgical revascularization in all patients treated with Clopidogrel [20-22].

Surgery should be performed using standard anticoagulation (heparin dosage, level of ACT) and anti-fibrinolytic (aprotinin) strategies [11,23]. Aggressive transfusion of platelets is required after termination of cardiopulmonary bypass - if used-before chest closure. If bleeding manifests on the intensive care, transfusion of platelets should not be delayed, independently of the platelet count.

\section{References}

[1] Quinn MJ, Fitzgerald DJ. Ticlopidine and clopidogrel. Circulation 1999;100:1667-72.

[2] Taniuchi M, Kurz HI, Lasala JM. Randomized comparison of ticlopidine and clopidogrel after intracoronary stent implantation in a broad population. Circulation 2001;104:539-43.

[3] Müller C, Buttner HJ, Petersen J, Roskamm H. A randomized comparison of clopidogrel and aspirin versus ticlopidine and aspirin after the placement of coronary-artery stents. Circulation 2000;101: $590-3$.

[4] Yusuf S, Zhao F, Mehta SR, Chrolavicius S, Tognoni G, Fox KK. Effects of clopidogrel in addition to aspirin in patients with acute coronary syndrome without ST-segment elevation. The Clopidogrel in Unstable Angina to Prevent Recurrent Events (CURE) Trial Investigators. N Engl J Med 2001;345:494-502.

[5] Moshfegh K, Redondo M, Julmy F, Wuillemin WA, Gebauer MU, Haeberli A, Meyer BJ. Antiplatelet effects of clopidogrel compared with aspirin after myocardial infarction: enhanced inhibitory effects of combination therapy. J Am Coll Cardiol 2000;36:699-705.

[6] CAPRIE Steering Committee. A randomised, blinded, trial of clopidogrel versus aspirin in patients at risk of ischemic events (CAPRIE). Lancet 1996;348:1329-39.

[7] Edmunds LH. Hemostatic problems in surgical patients. In: Colman RW, Hirsh J, Marder VJ, editors. Hemostasis and thrombosis: basic principles and clinical practice, 4th ed. ; 2001. p. 956-68.

[8] Levy JH, Smith PK. Platelet inhibitors and cardiac surgery. Ann Thorac Surg 2000;70:S1-S2.

[9] Patrono C. Antiplatelet strategies. Eur Heart J 2002;4:A49-A57.

[10] Steinhubl SR. Antiplatelet agents in cardiology: the choice of therapy. Ann Thorac Surg 2000;70:S3-S8.

[11] Levy JH. Platelet inhibitors and bleeding in cardiac surgical patients. Ann Thorac Surg 2000;70:S9-S11.

[12] Mochizuki T, Olson PJ, Szlam F, Ramsay JG, Levy JH. Protamine reversal of heparin affects platelet aggregation and activated clotting time after cardiopulmonary bypass. Anesth Analg 1998;87: $781-5$.
[13] Gansera B, Schmidtler F, Spiliopoulos K, Angelis I, NeumaierPrauser P, Kemkes BM. Urgent or emergent coronary revascularization using bilateral internal thoracic artery after previous clopidogrel antiplatelet therapy. Thorac Cardiovasc Surgeon 2003;51:185-9.

[14] Yende S, Wunderink RG. Effect of clopidogrel on bleeding after coronary artery bypass surgery. Crit Care Med 2001;29:2271-5.

[15] Hongo RH, Ley J, Dick SE, Yee RR. The effect of clopidogrel in combination with aspirin when given before coronary artery bypass grafting. J Am Coll Cardiol 2002;40:231-7.

[16] D'Ancona G, Donias HW, Karamanoukian RL, Bergsland J, Karamanoukian HL. OPCAB therapy survey: off-pump clopidogrel, aspirin or both therapy survey. Heart Surg Forum 2001;4:354-8.

[17] Essell JH, Martin TJ, Salinas J, Thompson JM, Smith VC. Comparison of thromboelastography to bleeding time and standard coagulation tests in patients after cardiopulmonary bypass. J Cardiothorac Vasc Anesth 1993;7:410-5.

[18] Mitka M. Results of CURE trial for acute coronary syndrome. J Am Med Assoc 2001;285:1828-9.

[19] Bhatt DL, Chew DP, Hirsch AT, Ringleb PA, Hacke W, Topol EJ. Superiority of clopidogrel versus aspirin in patients with prior cardiac surgery. Circulation 2001;103:363-8.

[20] Ley SJ. Quality care outcomes in cardiac surgery: the role of evidence-based practice. AACN Clin Issues 2001;12:606-17.

[21] Munoz JJ, Birkmeyer NJ, Dacey LJ, Birkmeyer JD, Charlesworth DC, Johnson ER, Lahey SJ, Norotsky M, Quinn RD, Westbrook BM, O'Connor GT. Trends in rates of reexploration for hemorrhage after coronary artery bypass surgery. Northern New England Cardiovascular Disease study Group. Ann Thorac Surg 1999;68:1321-5.

[22] Tuman KJ, McCarthy RJ, O'Connor CJ, McCarthy WE, Ivankovich AD. Aspirin does not increase allogenic blood transfusion in reoperative coronary artery surgery. Anesth Analg 1996;83:1178-84.

[23] Herbert JM, Bernat A, Maffrand JP. Aprotinin reduces clopidogrelinduced prolongation of the bleeding time in the rat. Thromb Res 1993;71:443-51.

\section{Appendix A. Conference discussion}

Dr Y. Balbaa (Cairo, Egypt): I would like to ask you, first, in this group of patients, did you use aprotinin or not?

Dr Englberger: All patients received at least 2 million units in the pump prime dose, and it was the decision of the surgeon if he wants to use the high dose protocol. The high dose protocol was more often used in the clopidogrel patient group, but despite this, we still had higher bleeding.

Dr Balbaa: My second question is, although the mean drainage for every patient was about $1.5 \mathrm{l}$, you had only a percentage of reoperation about $6 \%$. So what is your limits for taking back the patient to the operating room?

Dr Englberger: That was an observational study. We did not have really sharp limits of the chest drainage volume when we take the patients back, and if you look at the two other trials already published about this problem, sometimes the chest drainage will exceed more than 21 within $24 \mathrm{~h}$, but there is no take back to the OR.

If we expect that it is more a hemostatic derangement in the patients and not a surgical bleeding, then we really try-and you may know this also from your hospital-to correct the hemostatic competence of the patient first. During this time the drainage volume maybe will exceed more than 1.51 .

Dr Balbaa: And you can leave a patient draining 21 without taking him back to the OR?

Dr Englberger: I have seen such patients, yes. I think that is possible.

Dr P. Mortensen (Odense, Denmark): I am very pleased to see that you didn't use the surgeons as a risk factor for bleeding. Thank you for that.

What do you think about using epsilon-aminocaproic acid, it is called Cyklokapron in our country, instead of aprotinin? It is cheaper. 
Dr Englberger: We do not use these agents very often in our hospital. We are using always aprotinin, and we do not combine aprotinin with other antifibrinolytics. In this respect, I cannot answer your question.

But I know that up to now, no single clinical trial is available looking at the effect of aprotinin on patients who are treated with clopidogrel, and there is also no trial available looking at the synthetic antifibrinolytics. It is still a pure empirical decision to use these agents in this situation. But I think they will work.

Mr K. Rammohan (Cardiff, $U K$ ): It is very interesting because there is a huge percentage of inpatient referrals at the moment, and we face the same problem. The last slide alluded to the fact that your entire group is people who are on clopidogrel in the last three days. Am I correct in understanding that?

Dr Englberger: Yes.

Mr Rammohan: So people whose clopidogrel was stopped before that are completely excluded from what you mentioned. Is that a logical conclusion?

Dr Englberger: The patients who stopped clopidogrel three days prior to surgery are in the control group.

Mr Rammohan: And with the group that you have taken, and you again mentioned that there may have been an increased ACT, was it consistent that the clotting was deranged going into theater with all these people?

Dr Englberger: In some patients the ACT level is elevated when they come in. IV heparin use was the same in both patient groups, but in some patients you can see that the ACT is elevated if they are on multiple antiplatelets and/or also on heparin treatment. The recommendation I gave in the last slide was only in order to say that it is in our eyes not safe to reduce the intraoperative heparin dose due to an elevated ACT level at the beginning of surgery. This is often under discussion.

Mr P. Totaro (Swansea, UK): Why did you operate on patients who were still on clopidogrel or it was not stopped more than three days before? Were they all unstable patients?

Dr Englberger: The reasons to operate on them within three days are different. Patients in the clopidogrel group were more ill than the other patients. I have shown this. But we are also of the opinion that if you plan elective surgery, it is not strictly necessary to send the patients home if they are on clopidogrel. If we discussed this in the States where another legal surrounding exists, maybe we have to question this again. We are of the opinion surgery can be performed safely with a slightly elevated risk of bleeding in these patients.

Mr R. Ascione (Bristol, UK): I really would like to congratulate you on taking to our attention this important topic. We have paid a lot of attention to this too, and I would like to bring to this audience's attention our experience.

We have as a part of our internal clinical audit project done a study over a year, because we saw that we had an increasing number of referrals of urgent in-hospital patients with acute coronary syndrome coming through on a combination of clopidogrel plus aspirin and others. We divided all those urgent patients according to the preoperative antiplatelet/anticoagulation regimen into four groups. One group had all drugs stopped 5 days before surgery, because in the meantime they were stabilized; the other three groups had antiplatelet/anticoagulant drugs within 5 days prior surgery and they included: a group having aspirin alone, a group on clopidogrel either alone or plus aspirin, and a group having aspirin with IV heparin.

We carried out a risk-adjusted analysis to take account of all potential confounding variables including TIMI risk score.

Our results are pretty much in keeping with yours regarding blood loss and transfusion requirements. However, the use of clopidogrel either alone or associated with aspirin was also associated with higher in-hospital mortality and higher incidence of stroke, and we also had a higher 1-year mortality in this group.

Our message is that you can safely have clopidogrel up to five days before surgery, to maintain its benefit of reducing MACE events, but within 5 days prior surgery a more critical approach to these patients is required. Either one wait a bit longer, if the patient's clinical condition allows it, or one should switch them on something else like aspirin and IV heparin.

Dr Englberger: In our study group we did not see a difference in outcome. Maybe that has to be checked in a larger patient group. Otherwise your comment is in accordance to that I presented. 